\title{
Uses of sawdust as admixture in production of lowcost and light-weight hollow sandcrete blocks
}

\author{
Adebakin I. H. ${ }^{1^{*}}$, Adeyemi A. A ${ }^{2}$., Adu J. T. ${ }^{3}$,Ajayi F. A. ${ }^{4}$, Lawal A. ${ }^{5}$ and Ogunrinola O. B. ${ }^{6}$ \\ 1,2.3,4 Department of Civil Engineering, Yaba College of Technology, Lagos, Nigeria. \\ ${ }^{5}$ Department of Architecture, Yaba College of Technology, Lagos, Nigeria. \\ ${ }^{6}$ Department of Industrial \& Maintenance Engineering, Yaba College of Technology, Lagos, \\ Nigeria
}

\begin{abstract}
Prompted by the high cost of building materials as well as the amount of dead load weight generated by block wall on beams and columns in partitioning works most especially in high rise buildings, this project work on the use of sawdust as admixture in production of hollow sandcrete blocks was carried out in order to investigate a possible solution to the problems. The research work understudies the weight vis-a-vis cost of production of available commercial sandcrete blocks in Lagos metropolis. It has been observed that prices of construction blocks were typically above the reach of many Nigerians. Production of sandcrete blocks were made by partial replacement of sand with a varying proportion $(10 \%, 20 \%, 30 \%$ and $40 \%)$ of sawdust. The strength of each block was determined to ascertain conformity with the minimum acceptable standards. Equally, the weights were checked and compared with blocks devoid of sawdust. The tests were carried out on the 7, 14, 21 and 28 days after production. From data gathered, recommendations were given which will be beneficial to the construction industry and general populace in respect of low cost and light weight sandcrete blocks. It is concluded that if the recommendations herein should be followed, problems of cost and weight in building construction shall be reduced.
\end{abstract}

Keywords: Sandcrete, block, sawdust, admixture, light-weight, cost, building

\section{INTRODUCTION}

In recent years, home ownership for the middle and low income earners of the society is turning to be a mirage as building materials, construction costs and other factors has constantly put housing development at a very high cost. In developed countries, accommodation and home ownership is easier as governments and financial institutions have planned and effective housing policies and programmes to aid the citizenry in home ownership at affordable rates. In the developing world, especially in metropolitan African cities, scarcity of living accommodation has always been an issue. The available housing stock is diminishing by the day due to the high level of rural drift to urban centers.

Checking scarcity and high cost of building materials and the need to drastically reduce critical housing shortages, especially in the urban areas (and developing modern housing setups in the rural areas), have encouraged the search for alternative, innovative and cost effective building materials.
Aside concrete that is a major component of buildings and other engineering structures, sandcrete blocks form a major part to be recognized and put under consideration. Sandcrete blocks comprise of natural sand, water and binder. Cement, as a binder, is the most expensive input in to the production of sandcrete blocks. This has necessitated producers of sandcrete blocks to produce blocks with low OPC (ordinary Portland cement) content that will be affordable to people and with much gain.

The poverty level amongst West African Countries and particularly Nigerian has made these blocks widely acceptable among the populace so as to minimize the cost of construction works. For a long time until perhaps a few years ago these blocks were manufactured in many parts of Nigeria without any reference to any specifications either to suit local building requirements or for good quality work. The improper use of these blocks leads to micro cracks on the walls after construction. The use of alternative cheaper local materials as stabilizer will greatly enhance the production of sandcrete blocks with the 
desired properties at low cost. It will also drastically reduce the cost of production and consequently the cost of construction works.

In addition, the significance of this study was also necessitated due to the problem of dead load on load bearing components of building most especially in high rise buildings and places with soil of low bearing pressures.

The first objective of the present work was to investigate the use of sawdust as a partial replacement for sand in production of hollow sandcrete blocks in order to reduce production cost. The second objective was to understudy in line with the previous objective, to also produce light weight hollow sandcrete blocks for use in High rise buildings and buildings erected in region with low bearing capacity soils.

In the urban and rural areas of Nigeria, one can find sizable number of sawmills. They are mostly concerned with their finished-product therefore making the sawdust generated from such sawmills a waste. The main by-product of sawmills, unless reprocessed into particleboard, are burned in a sawdust burner or used to make heat for other milling operations, sawdust may collect in piles and add harmful leachates into local water systems, creating an environmental hazard. In developing countries like Nigeria, proper utilization of sawmills waste has not been given due attention. The sawdust thereby constitutes an environmental nuisance as they form refuse heaps in the areas where they are disposed. The use of sawdust as a partial replacement to sand will provide an economic use of the by-product and consequently produce cheaper blocks for low cost buildings.

\section{MATERIALS}

Sand is a naturally occurring granular material composed of finely divided rock and mineral particles. The composition of sand is highly variable, depending on the local rock sources and conditions. The sand used was collected from Gbagada River in Lagos, Nigeria and was clean, sharp river sand that was free from clay, loam, dirt and organic matter of any description and was sand passing through the $4.75 \mathrm{~mm}$ zone of British Standard test sieves. The sand had a specific gravity of 2.57 .

The type of cement used in this research is the Ordinary Portland Cement with properties conforming to BS 12 (1971), which happens to be the most commonly used in construction works.

Sawdust (SD) is composed of fine particles of wood. The physical and chemical properties of sawdust vary significantly depending on several factors, especially the species of wood. SD used in this research is a mixture of wastes from both hard and soft woods. Preliminary analysis was conducted on the sawdust to determine their suitability for block making. Tests conducted include: particle size analysis of sand, specific gravity test on Sawdust and sand. Majority of the fine particles of sawdust passed through $4.76 \mathrm{~mm}$ BS test sieve. The water used was potable water from borehole, which was fresh, colorless, odorless and tasteless water that was free from organic matter of any type.

\section{MATERIALS AND METHODS}

The minimum acceptable compressive strength of a good and well vibrated sandcrete blocks is $3.2 \mathrm{~N} / \mathrm{mm}^{2}$ at 28days. For the purpose of this work $150 \mathrm{~mm}$ by $450 \mathrm{~mm}$ hollow blocks were produced under laboratory condition. The mix ratio used was 1:8 (one part of binder to eight part of sand) at different replacement levels of sand and sawdust. For each replacement levels about 18 block samples were cast. The replacement levels and water/binder ratios used are as shown in Table 1.

Table 1. Percentage Replacement Levels \& Water / Binder Ratio

\begin{tabular}{|l|l|l|}
\hline \multicolumn{2}{|l|}{ Replacement level [\%] } & $\begin{array}{l}\text { Water/binder } \\
\text { ratio }\end{array}$ \\
\hline $100 \%$ sand, & $0 \%$ SD & 0.50 \\
\hline $90 \%$ sand, & $10 \%$ SD & 0.54 \\
\hline $80 \%$ sand, & $20 \%$ SD & 0.55 \\
\hline $70 \%$ sand, & $30 \%$ SD & 0.56 \\
\hline $60 \%$ sand, & $40 \%$ SD & 0.57 \\
\hline
\end{tabular}

Mix design was carried out by absolute volume method to select the most suitable materials (cement, $\mathrm{SD}$, sand and water) that will produce blocks with the desired properties. Compressive strength and density of the sawdust sandcrete blocks were also determined.

For the purpose of this study, Eighty-eight (88) numbers of $150 \mathrm{~mm} \times 450 \mathrm{~mm}$ hollow sandcrete blocks were produced. The quantities of materials obtained from the mix design were measured in each case

with the aid of weighing balance. The cement and sawdust (SD) was mixed thoroughly. The cement, SD 
and sand were then mixed together to obtain a homogeneous mixture. The measured quantity of water was then sprayed on to the mixture using bucket. The mixture was further turned with shovels until a mix of the required workability was obtained. The resulting mortar was transferred to the steel hollow mould to half the depth. This was thoroughly vibrated for an average period of two minutes (2mins.). The content was de-molded as a fresh hollow block. The block samples were cured by sprinkling water twice in the morning and evening daily. The molded blocks were later sent for compressive tests.

\section{RESULTS AND DISCUSSION}

Compressive Strength of Test Samples: The variations of compressive strength with age at curing are presented in figure 1. Water was continuously provided in the course of curing and the hydration process continued.

At the 28 days hydration period, only blocks made with $100 \%$ sand and $0 \%$ sawdust $\left(4.26 \mathrm{~N} / \mathrm{mm}^{2}\right.$ met the required standard for sandcrete blocks $(3.5$ $\mathrm{N} / \mathrm{mm}^{2}-10 \mathrm{~N} / \mathrm{mm}^{2}$ ). Few samples, at the $10 \%$ replacement, came closer to the standard and this could be taken as the optimum replacement level of sand with sawdust for strength criterion. At the 28 days hydration period, the range of strength obtained was between $4.26 \mathrm{~N} / \mathrm{mm}^{2}$ (for $0 \%$ sawdust content) to $1.80 \mathrm{~N} / \mathrm{mm}^{2}$ (for $40 \%$ sawdust content) as shown in figure 1. Test result indicates that the compressive strength decreases with increase in sawdust content for all ages at curing.

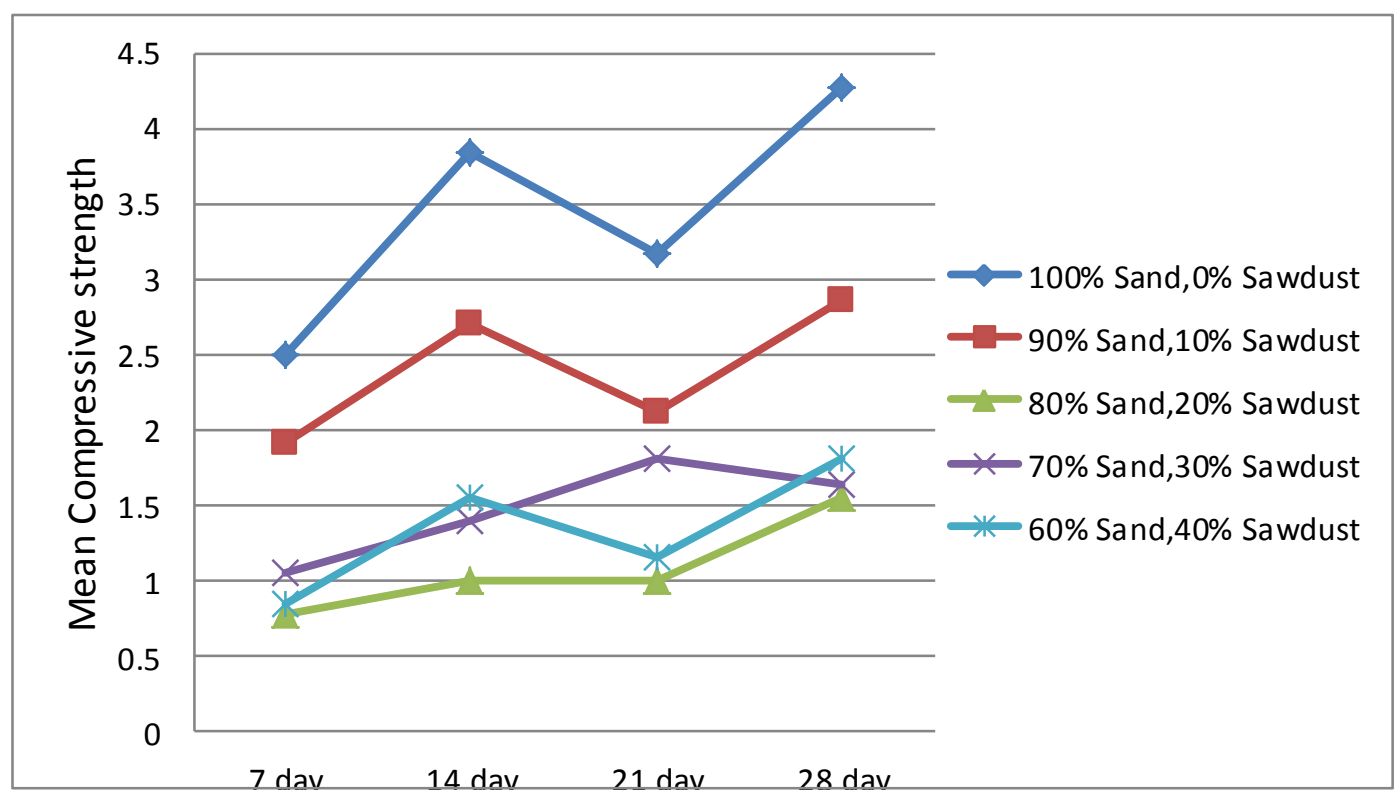

Fig 1. Graphical representation of average compressive strength of block samples 
Am. J. Sci. Ind. Res., 2012, 3(6): 458-463

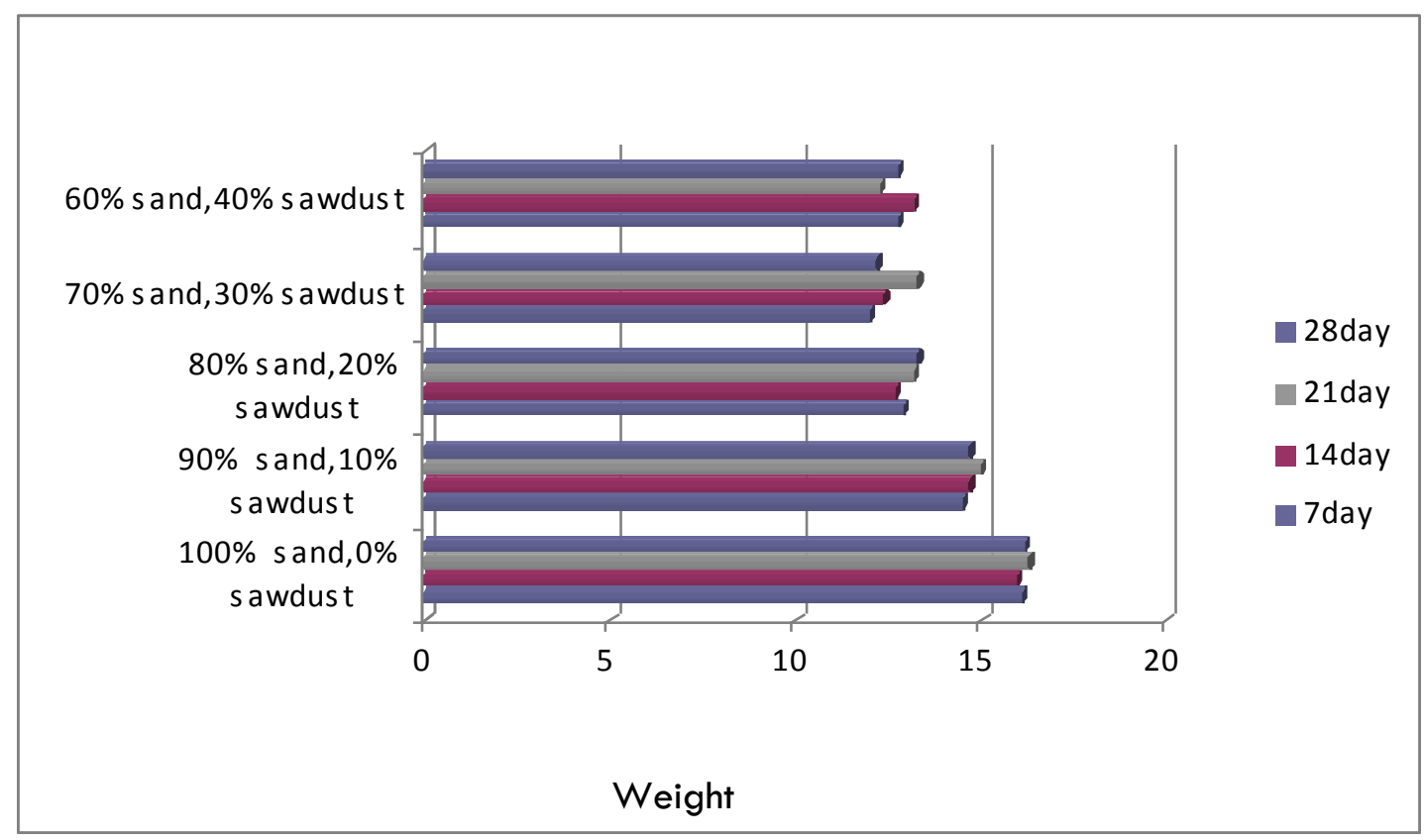

Fig 2. Graphical representation of average weight of block samples

compressive strength compared with sawdust replacement levels tend to a linear regression

Block Weights : The unit weight of each samples were taken and the result is as shown in figure 2 .

The results obtained shows that the introduction of sawdust reduced the unit weight of the hollow pattern, therefore the hypothesis relationship shall be written as:

Where

$$
I=\alpha+\beta E
$$

blocks according to the percentage added. There was, however, a significant decrease in samples with $10 \%$ sawdust replacement

Regression Analysis: For the purpose of this research a simple regression analysis is employed to ascertain the relationship between sawdust replacement in hollow sandcrete blocks and compressive strength. From the result gathered, the

$$
\begin{aligned}
& \alpha=\text { a constant amount } \\
& \beta=\text { the effect of sawdust replacement } \\
& E=\sum_{i=1}^{n} \underline{X} \\
& I=\sum_{i=1}^{n} \frac{Y}{n}
\end{aligned}
$$

The variable $\mathrm{I}$ is termed the "dependent" or "endogenous" variables; $\mathrm{E}$ is termed the "independent" variables; $\alpha$ is the "constant term" and $\beta$ the "coefficient" of the variable $E$. 
Am. J. Sci. Ind. Res., 2012, 3(6): 458-463

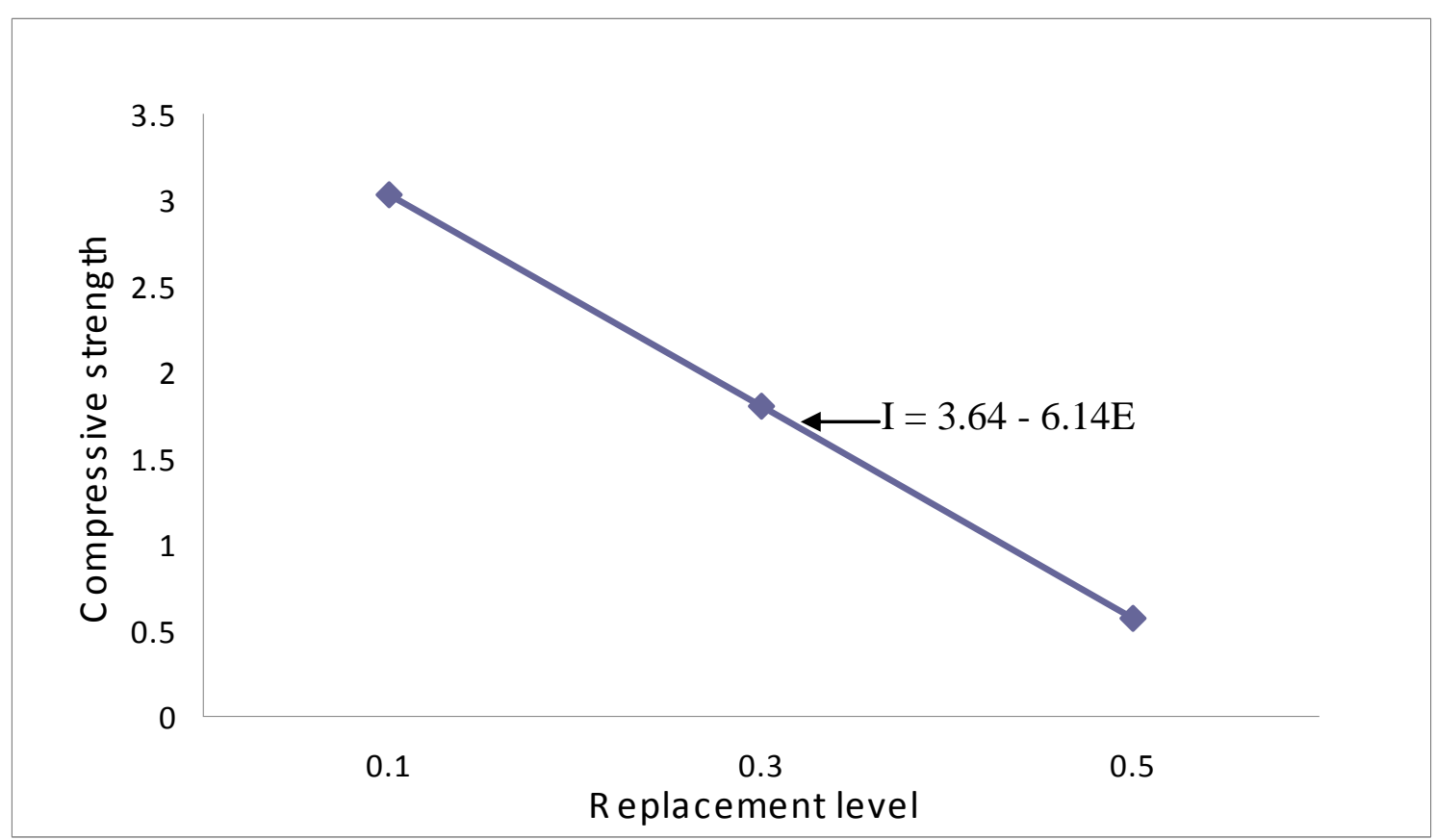

Fig 3. Graphical representation of regression equation at 28-day.

\section{CONCLUSION}

The following observations were made in the course of the research:

i. The volume of sawdust required to meet up with the replacement percentage required made proper mixing very tedious. Increase in the replacement level also increases the water ratio used.

ii. Attempt made at using $50 \%$ replacement of sand with sawdust was not successful as there the bonding was very poor.

iii. The research work confirms that the presence of tannin in sawdust acts as retarder, adversely affecting block strength.

iv. Though, as the percentage sawdust content increases in the mix, the compressive strength decreases. But, for the blocks manufactured with $10 \%$ replacement level however, the sawdust replacement did not appear to have a significant effect on the compressive strength of the sandcrete blocks.

v. The water /cement ratio increases as the percentage of sawdust increases.

vi. At $10 \%$ sawdust replacement, there is about $10 \%$ reduction in weight and $3 \%$ reduction in production cost.

It could, therefore, be concluded that: i. To achieve a better result in the use of sawdust for sandcrete blocks production, the percentage replacement of sand should not be more than $10 \%$.

ii. Whenever building weight is an important factor, then sawdust-sandcrete blocks could be a good option.

iii. Sawdust-sandcrete blocks are eco-friendly product.

iv. However, there is need for further studies on the fire resistance and standardization of hollow sandcrete blocks with sawdust replacement.

\section{REFERENCES}

1. Anwar, M. M. et al (2000): Using Rice Husk as Cement Replacement Materials in Concrete_Waste Management Series.

2. Buyukozturk, Oral \& Oguz, Gunes. (2004): High-Rise Buildings: Evolution and Innovations. Keynote Lecture CIB2004 World Building Congress Toronto, Ontario.

3. Hornbostel, C. ( 1991): Construction materials: types, uses, and applications, John Wiley \& Sons Inc., USA,. 271,

4. Ikponmwosa, E. E. \& Salau, M. A. (2007): Use of locally available raw materials for improved housing. (Department of Civil \& Environmental Engineering), University of Lagos, Akoka, Yaba, Lagos State, Nigeria 
5. Michael, K. O. (1994): Rice Husk as stabilizing agents in Clay Bricks, Higher National Diploma Project, Department of Civil Engineering, Federal Polytechnic Bida, Nigeria.

6. Olufolabo, O. O. \& Talabi, C. O. (2002): Principles and Practice of statistics: 193- 223.

7. Oluremi, A. A. (1990): Input of local Materials in Buildings as a Means of Reducing Cost of Construction, Journal of the Nigerian Institute of Quantity Surveyors. 12-14.

8. Oyekan, G.I. (2008): Effect of Admixtures on the Compressive Strength of Sandcrete

Blocks. Journal of Engineering and Applied Sciences 3 (Vol 6): 451-454.

9. Oyetola, E. B. \& Abdullahi, M. (2007): The use of rise husk Ash in low-cost sandcrete blocks production. Thesis of Department of Civil
Engineering, Federal University of Technology, Minna, Nigeria.

10. Paramaswam, P. \& Loke, Y O. (1978): Study of Sawdust Concrete. Proceedings of International Conference on Materials of Construction for Developing Countries Bangkok. Vol 1:169-179.

11. Revindarajah. R.S \& Appleyard. C. Caroll (2001): Development of Sawdust Concrete for Block Making. Centre for Infrastructure Research, University of Technology. Sydney. Australia.

12. Salau, M. A. (2008): Abundant local structural engineering materials without affordable structures. The Inaugural Lecture, Professor of Civil Engineering, University of Lagos, Lagos. 